\title{
Sexualidade, um direito (secundário)? Atravessamentos entre sexualidade, socioeducação e punição
}

\author{
Sexuality, a (secondary) right? Intersections on sexuality, \\ education and punishment
}

\section{Luisa Bertrami D’Angeloa e Jimena de Garay Hernandez}

Resumo Este artigo faz parte da pesquisa sobre sexualidade e juventude realizada de março 2015 a outubro de 2016, em três unidades de internação do Departamento Geral de Ações Socioeducativas do Rio de Janeiro, sendo duas unidades masculinas e a única unidade feminina do estado. A partir da perspectiva metodológica da cartografia, acompanhamos durante esses anos diversos processos nas unidades, entrevistando jovens e profissionais de diferentes segmentos. Apresentamos aqui reflexões sobre os debates que suscitamos no campo a respeito da sexualidade na socioeducação, procurando englobar as experiências e percepções dos/as jovens, dos/as agentes socioeducativos/as, do corpo de profissionais técnicos/as, do quadro docente e da direção, articulando os dispositivos de gênero, classe social, geração e raça para pensar nas produções de tecnologias e mecanismos de controle e na lógica punitiva que parece reger o cotidiano institucional. Pensando, assim, nas tensões que movimentam (ou cristalizam) os debates sobre sexualidade nestes contextos, propomos algumas reflexões a respeito de como a sexualidade é, também, alvo destas políticas punitivas e de contenção, uma vez que é classificada, hierarquizada, cerceada, vigiada e limitada nestes espaços.

Palavras-chave sexualidade; direitos; juventude; punição; privação de liberdade

\begin{abstract}
This paper is part of a research on sexuality and youth held from March 2015 to October 2016, in three Juvenile Detention Centers in Rio de Janeiro, two male and the only female in the state. From the methodological perspective of cartography, during these months we followed several processes in the centers, interviewing youngsters and professionals from different segments of the institution. We present here reflections on the debates that we raised in the field regarding sexuality in the juvenile justice system, seeking to encompass the experiences and perceptions of the youngsters, the agents, the technical staff, the professors and the direction, articulating the devices of gender, social class, generation and race to think about the
\end{abstract}

a Doutoranda no Programa de Pós-graduação em Psicologia Social na Universidade do Estado do Rio de Janeiro 
productions of technologies and mechanisms of control and in the punitive logic that seems to govern the institutional daily life. Bearing in mind the tensions that move (or crystallize) debates about sexuality in these contexts, we propose some reflections on how sexuality is also the target of these punitive and containment policies, since it is classified, hierarchized, monitored and limited in these spaces.

Keywords sexuality; rights; youth; punishment; deprivation of liberty

\section{INTRODUÇÃO}

Em face aos discursos conservadores que defendem a redução da maioridade penal no Congresso Nacional e em parcelas da população em geral, a temática da punição de jovens em conflito com a lei coloca e recoloca algumas questões como, por exemplo, a tensão entre aquilo que está disposto no ordenamento jurídico e nas regulamentações e orientações técnicas e aquilo que se configura como prática cotidiana nas instituições de privação e restrição de liberdade para jovens. Neste sentido, parece haver um gap entre aquilo que o Estatuto da Criança e do Adolescente (ECA) garante enquanto direitos e o que se efetiva neste campo no decorrer do cumprimento da medida socioeducativa. A punição, assim, estende-se para além do cumprimento da medida, a partir do momento em que não é possível sequer oferecer condições de garantia de direitos aos/às jovens inseridos/as no sistema socioeducativo.

Para além disso, cabe a discussão a respeito da própria proposta de socioeducação, uma vez que uma série de tensões se evidenciam quando buscamos pensar a coexistência de um sistema que, ao mesmo tempo que em pretende (re)educar, pune. Que sentidos termos como "ressocialização" ou "reeducação" tomam neste contexto? O que se quer com a punição destes/as jovens? $\mathrm{E}$ o que fazer frente à realidade de que o sistema seleciona os/as jovens pobres e negros/as como alvos de suas investidas, configurando-se um sistema altamente seletivo, arbitrário e violento?

Neste cenário, a questão dos direitos parece se dissolver numa série de demandas por condições mínimas de efetivação da aplicação da medida. No Rio de Janeiro, onde realizamos a pesquisa aqui apresentada, a superlotação - provinda, dentre outras coisas, de práticas de higienização da cidade -, as péssimas condições de saneamento e a falta de recursos humanos e financeiros - em um quadro de falência do estado -, fazem com que muitos/as gestores/as e profissionais do sistema pareçam entender que a garantia de qualquer outro direito que não seja entendido como "básico" não poderia estar, agora, na pauta de discussão. Para além do fato de que é complexo definir o que são direitos “básicos”, ou se existem 
direitos "supérfluos/secundários", é importante pensar de que forma se elegem os direitos que podem não ser garantidos frente à situação precária no sistema. Quanto a isso, parece que o exercício da sexualidade, foco da nossa pesquisa, tem sido uma faceta desses direitos difíceis de se garantir no sistema, talvez também por, muitas vezes, não ser entendida como um direito. Em pauta há alguns anos entre os/as gestores/as, equipes técnicas e especialistas, a questão da visita íntima tem se colocado como desafio neste campo, fazendo emergir uma série de debates, preocupações e discussões sobre como, quando e porquê implementá-la no sistema socioeducativo do Rio de Janeiro.

Para fazer ver as forças, poderes e saberes que atravessam essas discussões, é relevante pensar em alguns pontos que parecem ser centrais para a compreensão das dinâmicas de funcionamento deste sistema, como por exemplo as tecnologias de controle de determinados grupos sociais, a configuração do sistema socioeducativo como instituição de preservação da ordem (BICALHO; RossotTi; REISHOFFER, 2016) e a seletividade penal como um dispositivo que, articulando raça, classe, geração, gênero e geografia, seleciona alvos específicos a serem retidos pelas malhas do sistema.

\section{A PESQUISA}

Este texto faz parte da pesquisa sobre sexualidade e juventude realizada de março 2015 a outubro de 2016 em três unidades de internação do Departamento Geral de Ações Socioeducativas do Rio de Janeiro (Degase), sendo duas masculinas e a única feminina do estado. A equipe de pesquisa foi constituída por pessoas de graduação, mestrado, doutorado e corpo docente de diversas instituições: UERJ (Educação e Psicologia Social), IFRJ (Psicologia), FIOCRUZ (Saúde da Mulher) e UFRJ (Psicologia). A partir da perspectiva metodológica da cartografia (RoLNIK, 1989; Alvarez; Passos, 2009; Pozzana; Kastrup, 2009), acompanhamos durante esses anos diversos processos nas unidades, realizamos atividades em grupo e algumas entrevistas individuais com 65 jovens mulheres e 166 jovens homens, além de entrevistas com 81 profissionais de diferentes segmentos - equipe técnica, direção, escola, agentes socioeducativos/as e pessoal administrativo. Além disso, oferecemos um curso sobre gênero e sexualidade no cotidiano da socioeducação em uma das unidades masculinas, onde participaram 20 profissionais, e dois cursos na Escola de Gestão Socioeducativa, que também forneceram material para o debate. Igualmente, a discussão aqui apresentada se viu enriquecida por conversas com algumas pessoas da gestão que têm refletido sobre o assunto. 
A escolha pela metodologia cartográfica se deu por identificarmos nesta proposta possibilidades de pensar o campo a partir do que há de processual, de movimento (Pozzana; Kastrup, 2009, p. 56). Além disso, a cartografia permitiu que o nosso caminho se configurasse como uma pesquisa-intervenção, que não só não acredita na neutralidade como também pretende efetivamente movimentar o campo em que se insere (PASsos; KASTRUP, 2013, p. 273). Assim, pensando a pesquisa como compromisso ético-estético-político (Rolnık, 1993, p. 247), nosso objetivo foi produzir mudanças e estremecer barreiras.

Durante a pesquisa, a sexualidade apareceu como questão central na gestão cotidiana das unidades, seja por causa dos debates acerca da implementação da visita íntima, seja porque o exercício da sexualidade acontece com ou sem o aval da instituição. Desta forma, sexualidade emerge e é exercitada nas unidades de internação, restando duas opções: admitir sua existência ou ignorá-la. Escolhendo a primeira opção, temos buscado intervir neste campo de modo a suscitar debates a respeito do tema, procurando englobar as experiências e percepções dos/as jovens, dos/as agentes socioeducativos/as, do corpo de profissionais técnicos, do quadro docente e da direção.

O que observamos ao longo desses anos é que a sexualidade é atravessada por uma série de instituições que vão além da socioeducativa, como a família, as facções de tráfico de drogas, as comunidades religiosas, a mídia, entre outras. Deste modo, se coloca não só a discussão acerca de a sexualidade ocupar ou não um estatuto de direito, mas também (e talvez principalmente) sobre como a sexualidade passa a ser, no contexto das instituições de privação de liberdade, instrumento de controle dos corpos, na medida em que serve como "moeda de troca" para uma série de situações do dia a dia.

Além disso, à medida que se elege quem pode e quem não pode ter acesso a esse direito, entendido como tal, muitas vezes, apenas via visita íntima configura-se uma situação em que somente podem exercer a sexualidade aqueles/as que se enquadram num determinado modelo de jovem, com determinadas práticas que costumam estar voltadas à obediência, à docilidade dos corpos e ao controle. Como podemos pensar, então, os modos como a sexualidade é interpelada, controlada e gerida na instituição? De que formas a sexualidade embasa uma série de ações de controle e punição no cotidiano institucional? E também de que maneiras esses/ as jovens encontram brechas nesses controles para o exercício da sexualidade? A criação de possibilidades de prazer, de desejo e de afeto podem constituir-se como linhas de fuga? 
Nas discussões que fazemos sobre esse campo, entendemos sexualidade, gênero, geração, raça, classe social e geografia como dispositivos fundamentais para a compreensão da dinâmica institucional, da organização das unidades e da produção de subjetividades no contexto do Degase, sendo eles atravessados por uma série de outros equipamentos, práticas e discursos - atravessamentos estes que tecem uma complexa trama de poderes e disputas. Os dispositivos podem ser compreendidos como engrenagens que não existem a priori e não são naturais, mas históricas, construídas, que produzem sujeitos através de práticas discursivas e não discursivas (Foucault, 1999; Deleuze, 1989), que

se entrecruzam, representando às vezes linhas de fuga, às vezes resistências, às vezes mecanismos de sujeição, às vezes forças ou linhas de poder, às vezes formas de liberdade, enfim, criando um tecido que continuamente molda, detém, atrapalha e também gera brechas para escapar, sempre sendo constituintes de si (De Garay Hernández, 2013, p. 15).

No que tange ao dispositivo geração, nos parece interessante entender o processo histórico que tem delimitado a população que circula no sistema socioeducativo. Assim:

A construção da ideia de uma anormalidade biopsicossocial da juventude que se encontrava em condições socioeconômicas desfavoráveis estava estrategicamente inserida em toda a orientação (princípio) biológica do antigo Código de Menores. Sua proposta política era recolher os jovens "em situação de risco" para serem normalizados pelas tecnologias disciplinares de instituições cujos dispositivos concretos e efeitos arquitetônicos eram voltados especificamente para essa tarefa de gestão política da população jovem pobre brasileira (DA SILVA; Sereno, Gonçalves, 2014, p. 140).

O Código de Menores de 1927 nos dá uma ideia do contexto que levou à produção da necessidade de instituições de "socioeducação". Até o surgimento do Estatuto da Criança e do Adolescente, de 1990, as ações voltadas às crianças e jovens em perigo e aquelas/es tidas/os como perigosas/os eram as mesmas:

Pela legislação que vigorou no Brasil de 1927 a 1990 - o Código de Menores, particularmente em sua segunda versão -, todas as crianças e jovens tidos como em perigo ou perigosos (por exemplo: abandonado, carente, infrator, apresentando 
conduta dita anti-social, deficiente ou doente, ocioso, perambulante) eram passíveis, em um momento ou outro, de serem enviados às instituições de recolhimento. Na prática isto significava que o Estado podia, através do Juiz de Menor, destituir determinados pais do pátrio poder através da decretação da sentença de "situação irregular do menor" (ARANTEs, 2004, p. 163).

Neste cenário, era preciso criar instâncias que operacionalizassem medidas cabíveis para com estas crianças e jovens, sob o manto de "pena-tratamento ou uma pena-ressocialização" (ARANTEs, 2004, p. 163). É neste contexto que surge a noção de "menor infrator":

Assim, através de um artifício que transformou pobreza em irregularidade jurídica, a criança pobre passou a ser definida como "menor carente" ou "menor infrator" (hipóteses de situação irregular) e, através de um conteúdo médico psicosocial atribuído a estes menores, as medidas (ou penas) para sanar tal situação, dita de irregularidade, foram deslocadas para os próprios menores, e não para a situação. (ARANTES, 2004, p. 164).

Como apontado por Da Silva, Sereno e Gonçalves (2014), ao longo do tempo, essa "lógica menorista" tem sido desconstruída, incluindo o termo adolescente no lugar de menor, o que veio contestar a diferenciação feita pela sociedade entre os adolescentes das classes médias e os menores das classes populares baixas, (Trancoso; Oliveira, 2015; Schuch, 2009), com distinções raciais inegáveis. Nesse processo, o ECA tem sido fundamental, incluindo seu papel atual como “[...] instrumento de garantias de direitos, de contraposição às campanhas conservadoras que pregam o endurecimento de penas, a redução da idade penal e a implantação de uma política de tolerância zero" (DA Silva; Sereno; Gonçalves, 2014, p. 143).

No discurso promovido pela atual configuração do Degase, que inclusive se apresenta como Novo Degase, a instituição está passando por uma mudança de paradigma, como apontado por um gestor, “[...] de um foco na punição para algo que frisa a responsabilização dos/as jovens" ${ }^{\text {. }}$. No campo da pesquisa, observamos tentativas de substituição de termos como menor, menor infrator, bandido, pelo termo adolescente. Isto não implica na desaparição do uso desses termos, que além de serem frequentemente utilizados na mídia escutamos várias vezes no campo, sobretudo por parte dos/as agentes socioeducativos/as, mas também pelos/

1 Informação obtida em entrevista. 
as jovens. Em uma ocasião, ao perceber a nossa presença e escuta, uma agente reformulou a frase depois de usar o termo menor, apontando para uma vigilância do "politicamente correto" e lançando luz em uma importante discussão sobre se a mudança dos termos representa ou não uma mudança nas práticas punitivas e se aquela é suficiente para transformar as éticas das relações que se estabelecem neste contexto, muitas vezes ainda não pautadas na percepção do/a jovem como sujeito de direitos. Destarte,

[...] a aplicabilidade das leis e a efetivação das políticas públicas precisam estar atreladas à produção de um novo olhar para os jovens, sobretudo àquele em conflito com a lei, tendo em vista que a ele, ao longo da história, foram atribuídos adjetivos negativos que o excluem da possibilidade de exercer sua cidadania ( $D_{A}$ Silva; Sereno, Gonçalves, 2014, p. 143).

O uso recorrente da expressão o adolescente denota que o termo parece servir para classificar não somente um sujeito, mas um grupo de jovens, homens ou mulheres. O adolescente, assim, torna-se uma figura homogênea, uniforme, quase como um monstro que, conforme falou um agente socioeducativo, "[...] acha que pode tudo, que é contestador, rebelde, que quer mostrar que existe, que resiste"2. "Cheio de hormônios" "impulsivo", "raivoso", foram outros adjetivos usados por profissionais, além de "desequilibrada", "inconsequente" e "com os nervos à flor da pele", adjetivos que, associados às jovens mulheres, parecem ser evocados de modo a traduzir uma certa instabilidade do feminino a qual, quando atravessada pela geração, aparece de modo exacerbado.

Nesse sentido, concordamos com Da Silva, Sereno e Gonçalves (2014), assim como com Coimbra, Bocco e Nascimento (2005), ao pensar que o conceito de adolescente, utilizado no ECA e fundamental para um novo paradigma, carrega significados que pertencem a um viés desenvolvementista, biologizante e psicologizante, e que naturaliza as desigualdades sociais.

Atributos que enquadram a juventude em etapas (status) padronizadas, como se fosse um período universal no qual determinadas mudanças físicas, fisiológicas e hormonais, pertencentes a essa fase, seriam responsáveis por algumas características comportamentais. [...] Tais características passam a ser percebidas como uma essência em que "qualidades" e "defeitos" (rebeldia, desinteresse, crise,

2 Informação obtida em entrevista. 
instabilidade afetiva, descontentamento, melancolia, agressividade, impulsividade, entusiasmo, timidez, introspecção, tendência a expor-se a riscos, busca de identidade e formação de caráter) passam a ser sinônimos de adolescência, ou melhor, de adolescência problemática. E, dessa forma, esvaziam o caráter de resistência política frente às desigualdades e violências de todo o tipo (DA SiLva; SERENo, Gonçalves, 2014, p. 143-144).

Essas noções se articulam com as de pobre, marginal, bandido, vagabunda, seres que precisam ser docilizados. Nelas, é importante destacar de que formas os dispositivos de classe e raça atravessam a leitura desses corpos e se articulam com estas noções, tornando os/as jovens negros/as, especialmente de periferia, alvo principal de projetos de docilização, pauperização, criminalização e genocídio (Campos; Girotto, 2015; Calazans, 2015; Caetano; Scisleski, 2015; Ramírez, 2015; FERreira; CAPPI, 2016).

Assim, escolhemos não usar nas nossas análises os termos adolescente e adolescência. Como Cecília Coimbra, Fernanda Bocco e Maria Lívia do Nascimento (2005), preferimos o uso de juventude, e inclusive juventudes, que mesmo não resolvendo o impasse da cristalização de uma "fase da vida" - questão também apontada pelas autoras -, ou igualmente apresentando modelos específicos de viver (VIANNA, 1997), parece oferecer um entendimento da pluralidade, diferença e desigualdade nas experiências dos sujeitos considerados jovens. O foco, ao nosso ver, está no entendimento dos modos de inserção dos sujeitos em suas condições de vida históricas e concretas, as quais, por sua vez, têm múltiplas formas de serem apropriadas.

Aqui, revela-se uma tensão, pois ao tentar sair de uma visão adultocêntrica - ou seja, centrada na experiência adulta como a mais consciente, adequada e produtiva -, os discursos podem tentar contestar a proposta sem o devido aprofundamento. Por exemplo, no debate da redução da maioridade penal, tende-se a reivindicar que as/os jovens envolvidas/os em atos infracionais não têm a capacidade de refletir sobre seus atos da mesma forma que uma pessoa adulta. Aí, a perspectiva desenvolvimentista tem sido usada para reafirmar a adolescência como uma etapa com características e necessidade de cuidados particulares que o sistema prisional não pode outorgar. O debate, nesse sentido, parece focar no indivíduo como responsável ou não de cometer ilegalidades e não na produção social da desigualdade que delimita as fronteiras da legalidade, dos seres vítimas e/ou produtores dela e das punições e/ou outras formas de lidar com ela. 
Nessas tensões, podemos observar a relevância do atravessamento da sexualidade, já que, por outro lado, quem reivindica a redução da maioridade penal usa o argumento de que muito/as desses/as jovens "já" têm uma vida sexual ativa, e "inclusive são pais", como se essas experiências garantissem uma maturidade própria da vida adulta. Nessa lógica, questiona-se, como apontado por um agente socioeducativo, que sujeito é esse que "deve ser considerado uma criança, mas que tem uma vida sexual de adulto"? Vida sexual adulta que, inclusive, está tentando se reivindicar com a implantação da visita íntima.

Nesse sentido, nos perguntamos: o que diferencia ou deve diferenciar o sistema socioeducativo do sistema prisional? Para um jovem entrevistado na pesquisa, é justamente o direito da visita íntima que distingue a cadeia "de adulto" daquela em que ele está. Igualmente, um agente disse a visita íntima seria um retrocesso, “[...] porque os meninos vão achar que virou Bangu [referindo-se a uma prisão], com isso eles já teriam todas as coisas que uma prisão tem, então vão achar que são bandidos de verdade"3. Essas falas sugerem que a visita íntima delimita a experiência de punição de pessoas adultas, ao mesmo tempo mais rígida, para "bandidos de verdade”, mas com a garantia de certos direitos sexuais, e a de adolescentes, percebidos/as como "sementes do mal". Tal tensão nos faz pensar nas noções de sexualidade, geração e socioeducação, e nos provoca refletir sobre como propor argumentos que façam frente a discursos que pretendem legitimar um viés punitivista e naturalizador da "anomalia social" ao invés de uma perspectiva de garantia de direitos e de potencialização da vida como forma de atingir a igualdade social, é um grande desafio.

Assim, o conceito de trajetórias juvenis nos parece bastante útil para as discussões que estamos propondo.

A centralidade concedida à ideia de juventude como processo se operacionaliza na ênfase conferida à noção de trajetórias. Essa opção analítica desaloja a descrição estática da vida dos jovens em prol da recuperação de um movimento, não necessariamente linear, presente nos seus trajetos (HEILBoRn et al. 2002, p. 21).

No que diz respeito ao dispositivo de raça e sua articulação com geração, é importante insistir na seletividade penal racista como parte do fenômeno de genocídio da juventude negra (FERREIRA; CAPPI, 2016), incluindo a criminalização da cultura da periferia (SANTOS, 2016). Nesses processos, as instituições de segu-

3 Informação obtida em entrevista. 
rança pública e o judiciário desempenham lugares importantes de reprodução da discriminação. De que forma são produzidas as trajetórias juvenis da população negra, empobrecida, de periferia? E como as instituições de privação de liberdade viram importantes territórios dessa produção?

Zaffaroni (2003) chama a atenção para o fato de a "vulnerabilidade social" estar intrinsecamente ligada ao que ele chama de vulnerabilidade penal, visto que o sistema judiciário seleciona determinados sujeitos que serão retidos por suas malhas. O autor aponta que o "[...] grau de periculosidade que cada um de nós oferece ao sistema penal [...] depende de uma série de características, mais do que da conduta [...]. Não só a cara, mas as atitudes, o caminhar" (ZaFfaronI, 1990, p. 64), de modo que cria-se, assim, uma imagem de um tipo de jovem que será rebaixado ao posto de menor. Sobre esse "tratamento diferenciado", Zaffaroni (2007) ainda aponta que

A essência do tratamento diferenciado que se atribui ao inimigo consiste em que o direito lhe nega sua condição de pessoa. Ele é considerado sob o aspecto de ente daninho ou perigoso [...] estabelece-se a distinção entre cidadãos (pessoas) e inimigos (não pessoas), faz-se referência a certos seres humanos que são privados de certos direitos individuais (ZaFFARONI, 2007, p. 18).

Sobre a seletividade penal, é importante pensar os contornos particularmente complexos que o tema toma quando em face a uma política de drogas pautada na guerra, especialmente tendo em vista a quantidade de jovens no Degase envolvidos/ as com o tráfico de drogas e, principalmente, o fato de a maioria deles/as ocuparem posições hierarquicamente muito baixas na pirâmide de poder do tráfico. Ainda, é importante marcar os modos como o gênero atravessa as relações no tráfico e, também, engendra práticas diferentes dentro do próprio sistema. Nesse mosaico, em que a seletividade penal, o tráfico e o gênero se atravessam constantemente, fica evidente como a questão da punição está sendo o tempo todo perpassada por outros dispositivos, estratégias, mecanismos e instituições.

A inflexão do dispositivo gênero dá tonalidades particulares à seletividade quando, por exemplo, ouvimos o relato de uma jovem que havia sido apreendida para que a mãe não fosse presa no momento da batida policial, mesmo que as drogas encontradas na residência não fossem de nenhuma delas. O fato de estarem no domicílio quando ocorreu a ação policial fez com que fossem imediatamente associadas ao tráfico. Igualmente, escutamos um relato em que a mãe de um jovem, negra e moradora de favela, sofreu violência física deliberada por parte de policiais 
que chegaram na sua casa para prender o filho, dizendo "[...] faremos na senhora o que faríamos com ele"4.

Tais reflexões são potencializadas quando pensamos no que Cecília Coimbra (s/a) chama de "mito das classes perigosas" e na produção do medo como processo que constrói e reconstrói estereótipos sob os quais enquadram-se estes/as jovens cumprindo medida privativa de liberdade. Sobre a produção do medo, Coimbra (s/a) aponta que

[...] não só os sentimentos, mas todos os objetos que se encontram no mundo não existem em si, não têm uma essência, pois são forjados cotidianamente pelas práticas dos homens. Tais práticas são datadas historicamente e têm a capacidade de objetivar as coisas que estão no mundo. Assim diferentes práticas vão engendrando neste mundo objetos sempre diversos, diferentes "rostos", diferentes "fisionomias"; daí, não existir "medo e insegurança através dos tempos" ou "amor através dos tempos. (CoImBra, s/a, s/p)

A autora continua, apontando que o medo e a insegurança são produzidos com base em estereótipos a respeito dos sujeitos tidos como diferentes. As contribuições de Reishoffer e Bicalho (2009) permitem articular a produção de medo ao controle e à ordem social, visto que são os sujeitos que ameaçam estas instâncias aqueles que inspiram medo e insegurança. O controle, cujo objetivo é a manutenção dessa ordem, diz respeito não à dominação vertical de uma classe sobre outra,

Mas relações de força, vetores de dominação política (que podem estar localizados nas diferentes classes sociais e por todo corpo social) que buscam estratégias para manter e reproduzir relações sociais que desejam impor como naturais e normais. (REISHOFFER; BICALHO, 2009, p. 428).

A juventude negra, especialmente a masculina, é percebida como perigosa, incluindo sexualmente, o que evidencia mais uma articulação entre os dispositivos apresentados na nossa análise. Lidos como impulsivos, hipersexualizados, suas vidas e corpos aparecem como terminais dos riscos sociais, ao mesmo tempo em que uma exaltação de certa força física e a naturalização de características como "reprodutor", "bem dotado" e "viril” fazem parte do imaginário e do modelo hegemônico de masculinidade dos homens negros (CAEtano; Da Silva; De Garay, 2014).

4 Informação obtida em entrevista. 
No contexto do sistema socioeducativo, especialmente nas unidades de internação, marcadas pelo confinamento, falta de privacidade, permanente vigilância dos corpos e superlotação, muitos dos atravessamentos de sexualidade, gênero, raça, classe social e geração tomam novos contornos e têm efeitos específicos. Como apontado por Da Silva, Sereno e Gonçalves (2014), os corpos desses jovens, já marcados por certas características e perpassados por processos de subjetivação particulares, chegam a um espaço onde "[...] a repressão sobre seus movimentos é redobrada" (DA Silva; Sereno; Gonçalves, 2014, p. 138), não só por profissionais, mas por outros/as jovens. Nesse sentido, nos perguntamos de que forma a sexualidade, como dispositivo às vezes de controle, às vezes de fuga ou resistência, é vivenciado nas trajetórias por esses lugares. Diante disso, pensamos alguns temas que revelam atravessamentos desses dispositivos com noções e experiências de punição, direitos e violência.

\section{VISITA ÍNTIMA: DIREITO, PRESENTE, ESCÂNDALO OU MOEDA DE TROCA?}

O primeiro tema que nos parece relevante é a visita íntima. Como já mencionamos anteriormente, a sua implementação, preconizada no Sinase (Lei 12.594/12, BRASIL, 2006) no artigo 68, tem tensionado diversas posturas no que tange à sexualidade das/os jovens em privação de liberdade, mobilizando de diferentes maneiras as pessoas que se encontram inseridas no sistema socioeducativo.

No Rio de Janeiro, foi criado um Grupo de Trabalho (GT) interdisciplinar e interinstitucional para discutir a temática e de fato implementar o que o Sinase preconiza a respeito da visita íntima (SiLva; ZAMORA, 2014). Desse processo, algumas coisas chamaram a nossa atenção. Primeiramente, a opção pelo uso do termo visita afetiva no lugar de visita íntima parece explicitar o tom elegido pela instituição para trazer à tona este tema, pontuando duas questões relevantes: a preocupação em ponderar que a visita não diz respeito apenas à relação sexual, mas a um momento de convivência afetiva; e o que parece ser uma tentativa de tornar mais palatável a garantia do direito ao exercício da sexualidade desses/as jovens.

Em segundo lugar, há uma série de requisitos pelos quais os(as) jovens devem passar para pleitearem o direito à visita íntima: 1) casamento ou união estável comprovada - havendo a possibilidade de que a/o técnica/o de referência comprove essa união; 2) terem, tanto o/a jovem quanto a/o companheira/o, no mínimo 16 anos - sendo que nossas conversas com os/as jovens nos revelaram que a maioria deles/as já têm vida sexual ativa antes disso; 3) autorização de responsáveis legais ou da equipe técnica, quando for o caso - ponto difícil para as mulheres e para gays e lésbicas; 4) participação no Programa de Saúde e Sexualidade - ponto que 
nos pareceu ter muito potencial para discutir e exercitar a socioeducação, especialmente se não focar apenas na questão da saúde, mas na sexualidade como uma experiência humana perpassada por relações de poder e saber; e 5) cadastrar apenas um/a parceiro/a por passagem pelo sistema - sendo que, especialmente no caso dos homens, uma grande parcela mantêm relações com mais de uma pessoa ao mesmo tempo, e escolher um/a parceiro/a não estaria em seus horizontes.

Como é possível imaginar, existe uma dificuldade de se encontrar jovens que se adequem a essas expectativas. Além disso, diferentes moralidades parecem circular nos discursos sobre a sexualidade dos/as jovens, que se vêem, ao mesmo tempo, alvos de discursos que os colocam no campo da infância e da tutela e outros que, vinculando-os à vida adulta, legitimam o exercício da sexualidade. Sobre toda a confusão que o tema parece causar, presenciamos algumas situações que evidenciam essas tensões, como por exemplo quando uma técnica disse achar a proposta de visita íntima problemática uma vez que, se ela quando jovem não podia ter relações sexuais na casa dos pais, não havia razão para que o Estado aceitasse a ocorrência destas relações dentro das unidades. A confusão entre o público e o privado, entre a família e o Estado, mais uma vez apontam para a perpetuação e produção de discursos que não parecem ver a sexualidade como um direito, mas como um bem supérfluo que, concedido sob as condições da medida de internação, representaria algum tipo de benefício nada bem-vindo a quem deveria estar sendo punido.

Em uma entrevista com gestoras/es do Sistema, estas/es pontuaram distinções percebidas na implementação da visita íntima para homens e mulheres, imaginando que os homens jovens vão ter menos dificuldades para obter a autorização dos/as responsáveis, um dos requisitos da visita íntima, do que as mulheres. Ainda que na unidade feminina o discurso sobre sexo e sexualidade ocorra de maneiras muito mais "explícitas" do que na masculina - devido aos modelos de feminilidade e masculinidade hegemônicos -, sendo fato explicitado e evidenciado por jovens, agentes e outros/as profissionais a existência de relações entre elas, o tema da visita íntima parece trazer à tona uma série de moralidades e discursos a respeito "do feminino" que tornam a visita íntima para as jovens uma situação "mais delicada”, conforme apontado por um profissional.

Há, ainda, a preocupação com a gravidez, que levanta questionamentos por parte das/os profissionais da unidade feminina a respeito de como poderia o Estado justificar que uma jovem, menor de idade, sob sua custódia, teve relações sexuais e engravidou. Por outro lado, por ser o tema do uso de preservativos também um tabu, esse não se constitui como um argumento capaz de aplacar a preocupação da gravidez dentro da unidade. 
Tal temática também tem implicações particulares no caso de jovens lésbicas e gays, na medida em que nem sempre a orientação sexual deles/as é conhecida ou reconhecida pela família. Assim, exigir a autorização dos/as responsáveis pode suscitar situações de constrangimento e vulnerabilidade. Parece ainda haver uma resistência maior em fazer valer a visita para esses/as jovens, o que tem implicações diretas na noção de direitos sexuais e no exercício da sexualidade.

Isso evidencia outras questões que tocam as noções de autonomia e privacidade - que dentro de uma lógica que poderíamos chamar de "punições secundárias", parecem também ser afetadas, na medida em que a internação muitas vezes põe em suspenso tais direitos. Se, por um lado, esses/as jovens são menores de idade, por outro, o fato de serem reconhecidos/as como sujeitos de direitos pela lei deveria tornar possível o exercício da autonomia. O fato é que as relações sexuais já ocorrem nas unidades, por vezes atravessadas por violências e falta de cuidado. A distribuição de preservativos, no entanto, bem como iniciativas para falar sobre o tema, parecem constantemente esbarrar em barreiras práticas ou discursivas, visto que implicariam reconhecer que o exercício da sexualidade faz parte do cotidiano institucional.

Também é possível vislumbrar um discurso moralista que pretende garantir esse direito só para quem é "direitinho", “correto”, o que nos provoca pensar: o que significa "merecer" fazer sexo? Observamos, assim, que o controle da sexualidade relaciona-se com essas "punições secundárias", no sentido de que não basta estar privado/a de liberdade, é preciso também passar por uma série de outras privações. Um agente, por exemplo, foi muito enfático ao trazer exemplos de jovens que cometeram assassinato e estupro como não merecedores de tal direito - primeiro, como se estes fossem a maioria, e também como se seus atos desumanizassem suas existências. Articulando essa perspectiva à ideia da sexualidade como "benefício", conforme apontamos, a própria visita íntima transforma-se em um dispositivo de controle dos corpos.

Por fim, foram recorrentes as falas no sentido de pontuar que o sistema tem problemas muito mais sérios e urgentes, como a superlotação - em estado alarmantemente crescente, se multiplicando desde nossa entrada no campo ${ }^{5}$, a falta de recursos e a situação precária das unidades, e que, portanto, não seria viável falar deste tema no momento, já que o sistema não conta com algumas exigências básicas de higiene e saúde, novamente sugerindo que a sexualidade é um privilégio.

5 Os efeitos da superlotação nas vivências dos jovens no sistema socieducativo são evidentes, tais como a maior espera por audiência diante da sobrecarga das equipes técnicas, assim como a impossibilidade de garantir direitos de saúde, educação e higiene. 
As questões logísticas inviabilizariam a implementação, devido ao pequeno número de pessoal, especialmente de agentes - que já referem esta dificuldade na administração da visita familiar. Para além de a visita íntima não ser entendida como um direito que deve ser garantido, colocam-se evidentes as tensões entre punição e socioeducação, pois a ideia de que os/as jovens são "bandidos/as" bate de frente com a possibilidade de fazerem sexo dentro da unidade. Tal "regalia" faria não se cumprir o papel da instituição de punir os/as criminosos/as - que, além de serem menores de idade, cumprem penas curtas e "[...] podem ficar seis meses sem transar"6.

Outros agentes acham que se correria o risco de os jovens acharem que eles observam as companheiras com desejo, tal como acontece na visita familiar, o que geraria mais conflitos. Por outro lado, não sem serem questionados por colegas, alguns agentes comentaram achar interessante a proposta e consideram que poderiam usar essa visita como "moeda de troca", a depender do comportamento dos/as jovens:

Sabe-se que na instituição são estabelecidas relações de troca e privilégios que visam manter um certo apaziguamento das tensões. Ora o controle da "cadeia" (forma como os adolescentes nomeiam a instituição) está nas mãos dos internos, ora com a Direção. (DA Silva; SERENo, Gonçalves, 2014, p. 138)

\section{SEXUALIDADE EM PRIVAÇÃO DE LIBERDADE: PARA ALÉM DA VISITA ÍNTIMA}

A partir dos tensionamentos trazidos pela ideia da implementação da visita íntima, temos nos debruçado sobre a discussão, com jovens e profissionais, a respeito da vivência da sexualidade nas unidades, visibilizando que não é só nessa prática que a sexualidade e seus atravessamentos com as noções de direitos, punição e socioeducação aparece. Nesse processo, tem sido muito importante abordar as relações sexuais entre os/as jovens, tema extremamente velado no caso das unidades masculinas. Isso tem implicações ainda mais intensas no atual quadro de superlotação das unidades, em que o contato entre os corpos dos jovens é ainda maior, assim como o são os conflitos, a diminuição da privacidade e as violências.

Nesse sentido, alguns/mas funcionários/as relatam que um dos maiores problemas de saúde nas unidades são as epidemias de doenças sexualmente transmissíveis (DSTs), o que para elas/es evidencia que existem práticas sexuais entre os jovens e que elas não acontecem mediadas por cuidados de saúde7 . Porém,

6 Informação obtida em entrevista.

7 Apesar de ter funcionado como uma entrada muito propícia, sempre nos surpreendeu que a pesquisa, principalmente no início, fosse entendida como referente apenas a saúde sexual/ 
como já mencionamos, quando se fala em estratégias de distribuição de preservativos não só para as visitas íntimas, mas para o dia a dia das unidades, a maioria das/os profissionais considera isso desnecessário, ou inclusive acredita que isso "incitaria a que essas relações aconteçam e/ou sejam consideradas normais" como expressado por um agente socioeducativo.

É importante destacar que o fato de haver práticas sexuais entre os(as) jovens não significa que se possa supor que eles(as) são homossexuais ou que se autoidentifiquem como tal. Argumentos como a naturalização da pulsão sexual dos homens, a carência dos/as jovens e o estado de confinamento como circunstância que leva a essas relações circulam entre os/as funcionários/as. É preciso, ainda, identificar quando estas práticas são do campo do prazer e quando são do campo da violência.

Nesse sentido, é importante diferenciar as relações sexuais consensuais daquelas executadas em um contexto de violência, distinção certamente desafiadora e nem sempre feita pelas/os profissionais que são informadas/os sobre isso. Gostaríamos de falar, inicialmente, das segundas, mesmo concordando que a visão sobre sexualidade de jovens não deveria focar apenas sobre a violação dos direitos sexuais, mas no prazer, na expansão, na autonomia e nas experimentações (DA Silva; Sereno; Gonçalves, 2014, p. 140).

No cotidiano das instituições, escutamos relatos de violência sexual vivida e exercida pelas/os próprias/os jovens, também entendidas como forma de punição entre eles/as, ou como demonstrações de poder. Em uma ocasião em que estávamos em uma das unidades, uma profissional que ia realizar uma atividade de grupo com os jovens relatou que um dos que iam participar tinha sido estuprado por outros cinco no alojamento, provocando sérios ferimentos internos, a ponto de ele achar que estivesse grávido, mostrando a situação de desinformação do jovem sobre saúde sexual. Durante a atividade, ele nos relatou ter participado como cúmplice no estupro coletivo de uma jovem que estava saindo com ele. Pelo que percebemos, ele não relacionava uma violência com a outra, pois ele argumentava que a jovem era "rodada", por isso merecia tal tratamento. Dialogamos com ele, com os outros jovens e com a equipe de profissionais, procurando visibilizar a semelhança nas experiências e a desigualdade de gênero presente na percepção de quem merece viver essa violência e quem não. Ele expressou uma postura de reflexão diante do diálogo. Escutamos diversos relatos de violência sexual entre as/os jovens como

prevenção, sem considerar a sexualidade como uma experiência mais ampla e de afirmação de direitos, fenômeno que acontece em muitas iniciativas e políticas educativas voltadas à sexualidade de adolescentes (Da Silva; Sereno, Gonçalves, 2014). 
esse, a exemplo de uma situação na unidade feminina onde uma jovem teria sido estuprada por outras com um cabo de vassoura.

Nas instituições de socioeducação, as violências de gênero e as relações desiguais de poder se atualizam através de práticas e discursos que cristalizam modelos hegemônicos de masculinidade e feminilidade, atrelados à heteronormatividade - entendida aqui como o estabelecimento e incessante manutenção de um modelo de ser, se relacionar e se projetar no mundo baseado na heterossexualidade e na complementaridade dos gêneros (Junqueira, 2007, p.10). Assim, é possível identificar, mesmo nas relações sexuais e afetivas estabelecidas entre jovens mulheres, a reprodução do modelo heteronormativo de casal, no qual uma assume um papel opressor, controlador da outra, que deve permanecer submissa - o que resulta, dentre outras coisas, na manutenção da violência de gênero. Uma jovem, por exemplo, relatou que descobriu durante uma visita familiar que sua namorada estava com outra pessoa; disse, então, que quando saísse rasparia sua cabeça, regra estabelecida por algumas facções do tráfico para marcar as mulheres que acusadas de trair os homens.

Por outro lado, é importante pontuar que a violência sexual - assim como outros tipos de violência - não ocorre apenas entre os/as jovens. Escutamos relatos em que os agentes socioeducativos infligem este tipo de violência, seja no sentido de punir as/os jovens - por exemplo, forçar a lavar com sabão em pó e mangueira a genitália de dois jovens que ele encontrou tendo relações sexuais -, seja procurando algum ganho a partir do corpo das jovens - uma jovem, por exemplo, relatou ter mostrando os seios para um agente em troca de um cigarro.

Como já foi mencionado, há também relações sexuais consensuais, muitas vezes veladas, mas também justificadas pela já referida noção de adolescente como excessivamente sexual, sobretudo quando se articula com o dispositivo raça. Além disso, profissionais argumentam que esses sujeitos são carentes, diante das suas histórias de vida e especialmente ao estarem em privação de liberdade. No entanto, essas noções não fazem com que as relações entre as/os jovens sejam consideradas normais, pois, além da heteronormatividade, considera-se ser "típico do adolescente" uma "imaturidade" para tomar decisões sobre o seu corpo e a sua vida. Isso, portanto, faz com que essas práticas e suas implicações na saúde sexual não sejam abordadas no cotidiano das unidades em diálogo com os/as jovens, mas apenas em algumas atividades em formato de palestra, reduzindo possibilidades de elaborar essa temática em uma proposta de socioeducação. Observam-se poucas iniciativas de falar em direitos sexuais, expressões sexuais, conhecimento da sexualidade de forma mais ampla e formas não violentas de se relacionar. 
Esta questão se desdobra de formas distintas nas unidades masculinas e na feminina. No caso da feminina, é comum um posicionamento mais aberto em relação a relações sexuais entre elas, especialmente sob os argumentos da "carência", o companheirismo e o afeto, categorias naturalizadas como femininas, atrelando invariavelmente a sexualidade ao afeto. Esses argumentos são trazidos pelas/os profissionais e pelas próprias jovens, que parecem se apoiar estrategicamente no argumento já institucionalizado da "carência" para garantir que possam continuar se relacionando entre si. Igualmente, temos observado que as unidades tendem a permitir essas relações por uma percepção de que o sexo "acalma" a unidade, configurando a sexualidade como um mecanismo de apaziguamento. Dessa maneira, de forma variável e em ocasiões arbitrárias, esforços são feitos por parte da equipe de modo a possibilitar que os casais que se formam possam dividir o mesmo alojamento. Porém, as demonstrações públicas de afeto caracterizadas como "excessivas" pelos/as agentes - caracterização também arbitrária - podem trazer ações disciplinares de graus diversos, o que as leva a criar formas estratégicas de relacionar-se às escondidas.

No caso dos homens, como apontado por Da Silva, Sereno e Gonçalves , as unidades se configuram como "[...] um ambiente onde transitam discursos da 'cadeia', sendo esta um lugar para 'macho'. O ideário de uma masculinidade hegemônica parece assentar-se neste território" (2014, p. 132). Assim, códigos muito específicos de performatividades instauram permanentemente modelos de masculinidade, onde a homossexualidade é considerada uma traição e a heteronormatividade é em todo momento produzida e reproduzida. Desta forma, os jovens negam veementemente se relacionar sexualmente entre si nas unidades, embora já tenhamos escutado de agentes responsáveis pelos alojamentos - com nítido tom pejorativo - relatos de aproximações eróticas entre os jovens: abraços "muito" carinhosos, jovens "demorando muito no banheiro", dormindo de conchinha, colocando lençóis nos beliches, ganhando várias sobremesas e dizendo que "está 'fortalecendo' os outros", dentre outros. Os limites entre prazer, afeto, poder e violência são com certeza bastante vagos, mas é justamente no diálogo com os/as jovens sobre suas vivências, desejos e medos, que acreditamos que a instituição possa abordar a temática sem naturalizar, estatizar e/ou classificar essas experiências.

\section{POLÍTICA DE CONTENÇÃO: PRODUZINDO, VIGIANDO E LIMITANDO A SEXUALIDADE}

Apesar das linhas de fuga construídas pelos/as jovens, temos observado a permanência e intensidade de uma política de contenção da sexualidade, extremamente vigiada, especialmente nas unidades masculinas, entendida não apenas 
como contato físico em si, mas como uma série de fantasias, discursos, relações com o próprio corpo e com a forma de se apresentar no mundo. Isto pode ser revelado a partir de quatro elementos: a vestimenta das pessoas que circulam nas unidades, a masturbação, as cartas e fotografias e o tratamento dado a jovens gays e trans (travestis e transexuais).

Nos dias de visita familiares acontece um intenso labor logístico. Antes da recente implantação dos aparelhos de scanner, as/os familiares eram revistadas/os em busca de celulares, drogas, dinheiro e outros artefatos proibidos na unidade, o que provocava momentos constrangedores e conflituosos para eles/as e para as/os agentes, responsáveis por essa tarefa, tendo sido observadas, por exemplo, situações que culminaram na retirada de um piercing do clitóris. Diante disso, vários/as jovens comentaram não gostar que as famílias - especialmente as mulheres - os/as visitem, pois percebem a revista como humilhante. Aparentemente, a implantação do scanner tem "humanizado" o procedimento - termo usado por um gestor -, garantindo a intimidade e a dignidade das pessoas, mas não podemos deixar de pensar neste novo movimento como uma sofisticação das tecnologias de controle e de esquadrinhamento do corpo. O scanner, assim, não trata de ser somente um equipamento tecnológico para amenizar a humilhação da revista, mas também parte de toda uma política de controle que, pautada na prevenção, tenta justificar a necessidade de novos mecanismos de vigilância. Neste sentido, a implementação do scanner lança luz numa série de moralidades a respeito dos/as jovens e suas famílias, como evidenciado quando um agente comentou que a unidade feminina seria a última a receber o scanner, por se tratar de uma demanda "menos urgente" do que nas masculinas - o que nos leva a refletir a respeito da noção de periculosidade, certamente mais associadas aos jovens do que às jovens, especialmente quando pensada junto aos atravessamentos de raça.

Nas visitas, de forma muito semelhante às unidades prisionais para adultos, várias exigências são feitas a respeito da vestimenta, com especiais restrições para as mulheres: decotes, roupa curta, apertada ou transparente, dentre outras características que revelem partes do corpo entendidas como provocadoras de fantasias sexuais são proibidas institucionalmente, inclusive por escrito e colocado nas paredes. O motivo outorgado pelas unidades é a segurança ${ }^{8}$ : olhares e contatos que sugiram certa sexualização dessas mulheres - mães, irmãs, tias, esposas,

8 Cabe ressaltar que as preocupações logísticas e de segurança das unidades masculinas diferem da unidade feminina no que tange ao dia de visita, não só pela quantidade reduzida de mulheres em comparação aos homens, mas também e principalmente devido a uma série de construções acerca das masculinidades e feminilidades. 
namoradas - por parte de outros homens (jovens ou agentes) podem provocar conflitos entre quem lança o olhar e os jovens familiares das mulheres que são o alvo. Cabe discutir tal processo no campo das masculinidades, observando que é responsabilidade dos homens manter a honra das mulheres da sua família. Em extensão dessa normativa, as funcionárias das unidades também devem cobrir o corpo, evitando produzir "tentações" nos jovens. Inclusive, algumas têm usado (ou têm sido "convidadas" a usar) jalecos para esconder roupas "provocativas".

Mesmo sendo mais evidentes as normas para as mulheres, os jovens também seguem normas em que evitam mostrar o corpo durante as visitas familiares. Dependendo da unidade, no dia da visita colocam duas camisas ou a colocam por cima da bermuda, ao contrário do resto dos dias. Também se preservam com a maioria das funcionárias das unidades, por exemplo, não tirando a camisa na hora de fazer esporte, não falando sobre sexo e/ou corpo e não usando palavrões. Os agentes masculinos também relatam ter que acatar, em uma lógica de gestão de riscos, uma série de restrições nesses momentos, tais como não usar óculos escuros, não olhar para as familiares, não levantar suas camisas e não fazer movimentos que possam vir a sugerir uma certa expressão sexual, como coçar a barriga.

No final do curso sobre gênero e sexualidade no cotidiano da socioeducação ministrado em uma das unidades, em que participaram 20 profissionais, o professor de teatro preparou junto com os alunos duas esquetes relacionadas com o tema. A questão das vestimentas das técnicas foi um dos temas escolhidos, pela relevância e as controvérsias que levanta no dia a dia da instituição. Depois da apresentação, profissionais, jovens e nós pesquisadoras discutimos as percepções sobre o conflito apresentado. Os jovens confirmaram a importância das restrições nas vestimentas das técnicas e as familiares, e quando questionados sobre o fato de em outros locais (como a rua ou a praia) essa norma não se aplicar, um deles respondeu "[...] mas isto aqui é cadeia"9. Quer dizer, existe uma inflexão específica no momento em que se entra nesse estabelecimento, em que o controle dos corpos e a contenção da sexualidade atuam com intenso rigor, não só por parte do Estado, mas pelos próprios jovens - especialmente aqueles pertencentes às instituições do tráfico.

Teixeira (2015) chama a atenção para como as instituições de socioeducação, enquanto instituições de privação de liberdade, atualizam e produzem novas tecnologias e estratégias de controle e punição, estando estas ligadas à "centralidade da

9 Entrevista concedida por TAL, Fulana de. Entrevista I. [mês, ano]. Entrevistador: Siclano. Cidade, data. 
pena privativa de liberdade" (TEIXeIRA, 2015, p. 230) nos modelos penais atuais - que, em grande parte, respondem a uma demanda de determinados setores por leis mais rígidas. A resposta do Estado à sensação de insegurança tem, assim, privilegiado uma política pautada na exclusão e na contenção, ainda que o ECA tenha representado um significativo avanço na construção de uma política assentada em outro modelo. Assim, falas recorrentes sobre o Degase "virar cadeia depois das 17 h" evidenciam as tensões que, como Teixeira (2015) também já apontou, habitam as políticas públicas para jovens em conflito com a lei, que conjugam leis rígidas e garantias processuais penais, repressão rigorosa e penas alternativas e uma economia punitiva junto de uma proposta de garantia de direitos, questão que se complexifica ao falar de direitos entendidos como secundários, como os direitos sexuais e reprodutivos.

De maneira semelhante, em uma lógica de contenção da sexualidade articulada com uma construção de uma masculinidade em que os homens são responsáveis de preservar a honra das mulheres, temos escutado inúmeras vezes que os jovens têm normas muito sólidas no que tange à prática da masturbação. Tais normas são impostas pelo tráfico - que, podemos pensar, também pune a quem está privado de liberdade, talvez por ter sido pego, talvez por tentar reafirmar seu pertencimento a esse grupo - e implementadas por eles, se estendendo ao alojamento. Segundo essas normas, os jovens nas unidades não podem "quebrar" - se masturbar - nem no próprio dia e nem no dia seguinte à visita familiar, já que, nesta lógica, poderiam estar pensando em alguma das mulheres das famílias dos outros. Tampouco podem olhar as fotos das companheiras que os outros recebem, outra complicação considerando a situação atual de superlotação. A justificativa é sempre a ameaça de retaliações por descumprimento dos códigos das facções do tráfico. Apesar de termos ouvido linhas de fuga a essa regra em entrevistas individuais, sua rigidez é perceptível, desdobrando-se em retaliações que podem ser até mesmo letais.

Igualmente, tais cartas e fotografias recebidas pelos jovens homens, principalmente vindas de parceiras sexuais e amorosas, representam uma insistente preocupação com a "segurança", apontando a necessidade de uma triagem, prática de controle - e inclusive de punição - em que geralmente a equipe técnica torna-se responsável por fazer um filtro do que pode ou não ser entregue aos jovens. Na triagem, as cartas e fotografias com conteúdo considerado erótico não são entregues, e as técnicas acabam habitando um complexo lugar entre vigias e cuidadoras dos jovens. Vale ressaltar que tal prática é questionada por muitas das técnicas e inclusive condenada pelo Conselho Regional de Psicologia, considerando que a mesma fere o Código de Ética da profissão ao negar o direito à privacidade. 
No caso de homens gays e mulheres trans que chegam nas unidades femininas, podemos observar uma evidente contenção da sexualidade, que pode configurar uma violação à expressão da orientação sexual/identidade de gênero. Ainda que pouco numeroso - justamente por esses/as jovens não se enquadrarem nas normas de gênero das facções do tráfico -, o ingresso de jovens gays parece desestabilizar a operacionalidade das unidades. Como já foi abordado, essas também reificam a produção e a afirmação do modelo de masculinidade, ameaçado pela transgressão da norma heterossexual e da identidade de gênero masculina. A maior parte dos jovens e, cabe destacar, também alguns/as funcionários/as das unidades, partilha de noções extremamente homofóbicas e transfóbicas, cujas expressões temos testemunhado ao longo da pesquisa: ora com violentas reações ao tema e com o relato de práticas de extrema violência a pessoas LGBT, ora com um discurso que se pretende mediador - justificando-se na homofobia dos jovens -, seu conteúdo é altamente heteronormativo - como quando, por exemplo, sugerem que os jovens gays deveriam "ser mais discretos".

Como apontado por Da Silva, Sereno e Gonçalves (2014):

O espaço de convivência na instituição socioeducativa traz, por analogia, um ranço do sistema prisional e com ele o lugar do "macho" reina, existindo pouco, ou quase nenhum espaço, para o diferente [...]. Nesta lógica, o jeito mais imediato de lidar com o não homem é isolá-lo, excluí-lo, tornando-o invisível, muitas vezes com a justificativa de uma suposta proteção. (DA Silva; Sereno, Gonçalves, 2014, p. 135-136)

Assim, observamos que os jovens gays, chamados de "mancões", são alocados no alojamento chamado de "seguro", dividindo este espaço com os "Jack", aqueles que entraram no sistema por terem cometido/sido acusados de cometer estupro, sob a alegação de que sua segurança não poderia ser garantida se ficassem nos alojamentos coletivos. Entretanto, o risco de serem agredidos é constante, mesmo estando no "seguro".

Tal separação não ocorre na unidade feminina, visto que, como já foi apontado, o fato das jovens se relacionarem entre si tem melhor aceitação. Nessa unidade, tanto as/os funcionárias/os quanto as próprias jovens afirmam que são minoria aquelas que não mantêm nenhuma relação com outra jovem na unidade; do mesmo modo, todas(os) parecem acatar as separações de gênero que se estabelecem na unidade. As jovens se denominam “João" quando se trata daquelas que performam uma certa masculinidade, vestem roupas masculinas, adotam ou não nomes 
masculinos e ocupam "o lugar do homem”, nas palavras delas. Já as "Maria” são o que elas chamam de "lésbicas", diferente das "sapatões" - aquelas têm traços e jeitos comumente entendidos como "mais femininos" e seriam, portanto, também em suas palavras, "as mulheres da relação". Entre João e Maria se estabelecem relações fortemente marcadas pela reprodução da heteronormatividade.

No caso das mulheres trans, há pequenos e intermitentes avanços no seu encaminhamento à unidade feminina e no reconhecimento dos seus nomes sociais e suas performatividades femininas (incluindo cabelo e vestimenta), mas não isentos de desconforto e conflitos logísticos, muitas vezes invisibilizados. Há, atualmente, duas jovens trans internadas na unidade feminina, sendo que a primeira delas passou quatro meses em uma unidade masculina antes de ter garantido seu direito de cumprir a medida em unidade compatível com sua identidade de gênero. Elas estão alocadas separadamente das outras jovens, o que tem resultado em conflitos tanto para elas - que muitas vezes não entendem a razão da diferenciação - quanto para as demais jovens, que veem neste movimento uma atenção diferenciada às jovens trans. A situação tem causado desconforto, até mesmo porque alocá-las em alojamentos separados num cenário de superlotação implica em colocar um número ainda maior de jovens por alojamento. A instituição justifica a separação afirmando que a principal preocupação seria uma destas jovens “engravidar alguém”, fato que mobiliza todas as problemáticas já elencadas anteriormente sobre o tema gravidez em instituições de privação de liberdade, especialmente com menores de idade.

É interessante notar que a presença destas jovens trans tem desestabilizado e movimentado sobremaneira o cotidiano institucional, tanto no sentido de haver tentativas de discutir a temática e produzir novas práticas que deem conta desta diversidade quanto, também, no sentido de reforçar a heteronormatividade e as hegemonias de um feminino que não parece contemplar a transexualidade como igual possibilidade de performatividade do feminino.

Vale ressaltar ainda que a presença dessas jovens trans resultou no reconhecimento por parte de outras jovens que vivenciavam experiências de gênero mais fluidas - transitando entre homem e mulher - da possibilidade de serem homens trans, tendo alguns deles reivindicado o reconhecimento de suas identidades e o uso de nomes sociais. Nesses casos, não parece haver mobilização no sentido de transferi-los para as unidades masculinas. Alguns já demonstraram desejo de ser transferidos, mas a instituição insiste que fazê-lo significaria vulnerabilizá-los e expô-los a potenciais violências sexuais que eles poderiam vir a sofrer por parte dos outros jovens por serem homens trans. Assim, parece que a instituição se vê dividida entre reconhecer e respeitar a identidade de gênero desses jovens e uma 
série de outros direitos entendidos como concorrentes a pesarem na balança - e nesta parece que o direito à integridade física e à não-violência acabam sendo entendidos como mais importantes, porque mais arriscados, do que o direito a cumprir a medida em unidade em conformidade com suas identidades de gênero. Talvez, exatamente por se verem obrigados a escolher o "maior" direito, temos observado estes esforços de reconhecimento dos nomes sociais na unidade feminina.

\section{ALGUMAS CONSIDERACÕ̃ES FINAIS}

Frente a todas as dificuldades até aqui apresentadas no que tange à sexualidade e direitos sexuais - desinformação, vulnerabilidade, violência, discriminação e inclusive contenção -, tem nos mobilizado a necessidade de tirá-los de um status de questão secundária e integrar sua discussão à noção de socioeducação. É justamente nesse sentido que, quando nos foi mencionada a proposta de incluir um programa sobre saúde e sexualidade na implementação da visita íntima, consideramos que este momento poderia apresentar uma possibilidade de pensar formas de abordar esses temas com todas as pessoas que circulam no sistema socioeducativo, incluindo profissionais, gestores/as, jovens e suas famílias e também grupos de pesquisa ${ }^{10}$. É também com esse objetivo que a nossa pesquisa tem se inserido, dentro do possível, nas movimentações das unidades.

Ao longo da pesquisa, foi possível revelar a articulação dos dispositivos de sexualidade, gênero, geração, classe social e raça na lógica da punição e do cerceamento da plena cidadania. Entendendo o exercício da sexualidade como direito fundamental e buscando identificar os processos que parecem controlar, limitar e vigiar a sexualidade em contextos de privação de liberdade - especialmente aqueles ocupados por jovens em conflito com a lei -, buscamos refletir a respeito das práticas, discursos e poderes que criam mecanismos de controle e fazem da sexualidade uma moeda de troca, um direito secundário e uma via para a manutenção de uma lógica punitiva, engendrando inclusive punições secundárias.

Assim, através de algumas problematizações às noções cristalizadas no que se refere a esses dispositivos, buscamos contribuir na elaboração de pistas para subverter a lógica dessa articulação e propor outros repertórios, na busca de autonomia, prazer, garantia de direitos e vida. Destarte, mesmo que muito tímidas, atividades desenvolvidas na nossa pesquisa no sentido de propor o diálogo entre todos os que circulam no sistema socieducativo e a desnaturalização de práticas

10 Por sua vez, essa discussão poderia ser levada ao Judiciário, no intuito de que este se perceba como parte da socioeducação. 
violentas, códigos enrijecedores e classificações limitadoras, pareceu apontar caminhos interessantes.

\section{REFERÊNCIAS BIBLIOGRÁFICAS}

Alvarez, Johnny; Passos, Eduardo. "Cartografar é habitar um território existencial”. In: Kastrup, Virginia; Passos, Eduardo; Escóssia, Liliana da (org.). Pistas do método da cartografia: pesquisa-intervenção e produção de subjetividade. Porto Alegre: Editorial Sulina, 2009, p. 131-149.

Arantes, Esther M. M. De "criança infeliz" a "menor irregular" - vicissitudes na arte de governar a infância. Mnemosine, v. 1, n. o, p. 162-164, 2004.

Bicalho, Pedro; Rossotti, Bruno; Reishoffer, Jefferson. A pesquisa em instituições de preservação da ordem. Rev. Polis e Psique, v. 6, n. 1, p. 85-97, 2016.

BRASIL. Sistema Nacional De Atendimento Socioeducativo - SINASE. Secretaria Especial dos Direitos Humanos. Brasília: CONANDA, 2006.

Caetano, Carla; Scisleski, Andrea. "Produção de vida e morte jovem: psicologia entre os caminhos de liberdade e segurança”. In Accorsı, et al. (orgs) Distintas faces da questão social: desafios para a psicologia. Florianópolis: ABRAPSO, 2015, p. 113-127.

Caetano, Marcio; Da Silva, Paulo; De Garay, Jimena. Ninguém nasce homem, torna-se homem: as masculinidades no corpo e o corpo nas práticas curriculares das masculinidades. Revista Periódicus, v. 2, nov. 2014-abr. 2015.

Calazans, Márcia. "Homicídios de jovens em Salvador e as novas tessituras das cidades". In Caniato, Angela, et al. (orgs). Psicologia social, violência e subjetividade. Florianópolis: ABRAPSO, 2015, p. 81-103.

CAmpos, Letícia; Grotтo, Willian. "Violência de Estado e juventude: problematizando atos infracionais". In CANiATo, Angela, et al. (orgs). Psicologia social, violência e subjetividade. Florianópolis: ABRAPSO, 2015, p. 388-401.

Cormbra, Cecília; Bocco, Fernanda; Do Nascimento, Maria Livia. Subvertendo o conceito de adolescência. Arquivos Brasileiros de Psicologia, v. 57, n. 1, 2005, p. 2-11.

Cormbra, Cecília. Produção do medo e da insegurança. Disponível em: http://www.slab. uff.br/images/Aqruivos/textos_sti/Cec\%C3\%ADlia\%20Coimbra/texto64.pdf. Acesso em: 24 de janeiro de 2017.

Da Silva, Juraci; Sereno, Graziela; Gonçalves, Hebe. "A visita íntima de adolescentes no sistema socioeducativo como dispositivo de enunciação de questões relativas às sexualidades”. In Julião, Elionaldo; Abdalla, Janaína; Vergílio, Soraya (orgs). Delinquência juvenil, políticas públicas e direitos humanos. Rio de Janeiro: Novo Degase, 2014, p. 131-151. 
Deleuze, Gilles. “Qu'est-ce qu'um dispositif?”. Association pour le Centre Michel Foucault Michel Foucault philosophe. Paris: Seuil, 1989, p.185.

De Garay Hernández, Jimena. Filhas de famílias homoparentais: processos, confrontos e pluralidades. Dissertação (Mestrado em Psicologia Social). Instituto de Psicologia da Universidade do Estado do Rio de Janeiro, Rio de Janeiro, 2013, 197 p.

FERREIRA, Poliana; CAPPI, Riccardo. Contando as mortes de jovens negros: narrativas de um real insustentável. Cadernos do CEAS, n. 238. Salvador, p. 543-467, 2016.

Foucault, Michel. "Bruxaria e loucura" In: Ditos e Escritos I. Rio de Janeiro: Forense Universitária, 1999, p. 320-323.

HeIlborn, Maria Luiza et al. Aproximações socioantropológicas sobre a gravidez na adolescência. Horizontes Antropológicos, v. 8, n. 17, Porto Alegre, 2002, p. 13-45.

JunqueIra, Rogério. Homofobia: Limites e possibilidades de um conceito em meio a disputas. Revista Bagoas, v.1, 2007, p. 1-22.

PAssos, Eduardo; KASTRUP, Virgínia. "Sobre a validação na pesquisa cartográfica”. Fractal, Rev. Psicol., v. 25, n. 2, 2013, p. 391-414.

Pozzana, Laura; Kastrup, Virgínia. "Cartografar é acompanhar processos". In Kastrup, Virginia; PAssos, Eduardo; Escóssia, Liliana da (org.): Pistas do método da cartografia: pesquisa-intervenção e produção de subjetividade. Porto Alegre: Editorial Sulina, 2009, p. 52-75.

Ramírez, Héctor. Criminalidad y racismo: una aproximación desde la obra de Michel Foucault. La Manzana, v. 9, n. 12, 2015, p. 65-81.

Reishoffer, Jefferson; Bicalho, Pedro. Insegurança e produção de subjetividade no Brasil contemporâneo. Fractal, Revista de Psicologia, v.21, n.2, 2009, p. 425-444.

RoLNIK, Suely. Cartografia sentimental: transformações contemporâneas do desejo. São Paulo: Estação liberdade, 1989.

Pensamento, corpo e devir Uma perspectiva ético/estético/política no trabalho acadêmico. Cadernos de Subjetividade, v.1 n.2, 1993, p. 241-251

SANTos, Maristela. Cultura da periferia e o olhar do poder judiciário: a questão da apologia ao crime. Cadernos do CEAS, n. 238. Salvador, 2016, p. 627-640.

Silva, Maria Tereza; Zamora, Maria Helena. Visita íntima no sistema socioeducativo do Rio de Janeiro: uma construção interdisciplinar. Rev. Bras. Adolescência e Conflitualidade, v. 11, 2014, p. 1-13.

Teixeira, Joana D. Sistema socioeducativo em questão: as tensas relações entre o punitivo e o socioeducativo. Rev. Bras. Adolescência e Conflitualidade, v. 12, 2015, p. 223-254. Trancoso, Alcimar; Oliveira, Adélia. "Conceito dinâmico de juventudes e sua implicação na política pública”. In CANiATo, Angela et al (orgs): Psicologia social, violência e 
subjetividade. Florianópolis: ABRAPSO Edições do Bosque CFH/UFSC, 2015, p. 242-259.

Schuch, Patrice. Práticas de justiça. Antropologia dos modos de governo da infância e juventude no contexto pós-ECA. Porto Alegre: UFRGS Editora, 2009.

Vianna, Hermano. "Introdução". Em Vianna, Hermano (org). Galeras Cariocas: territórios de conflitos e encontros culturais. Rio de Janeiro: UFRJ, 1997.

ZAFFARONI, Eugenio. A criminologia como instrumento de intervenção na realidade. Revista da Escola do Serviço Penitenciário do Rio Grande do Sul, v. 1, n. 4, Porto Alegre, jul./ago./set. 1990.

O inimigo no Direito Penal. Rio de Janeiro: Revan, 2007.

Zaffaroni, Eugenio R.; Batista, Nilo. Direito Penal Brasileiro, $1^{\circ}$ vol., 2. ed. Rio de Janeiro: Revan, 2003. 